\title{
Trabalho e formação docente na Escola Técnica de Goiânia: política, ideologia e produtividade
}

\author{
Work and teacher training in the Goiânia Technical School: politics, ideology, \\ and productivity \\ Trabajo y formación docente en la Escuela Técnica de Goiânia: política, \\ ideología y productividad \\ DENISE SILVA ARAÚJO \\ HELVÉCIO GOULART MALTA DE SÁ \\ IRIA BRZEZINSKI
}

\begin{abstract}
Resumo: Pretende-se, neste trabalho, analisar um dos marcos estruturantes da produtividade na formação dos professores da educação profissional, para compreender a ideologia que fundamentou o trabalho docente nessa modalidade de ensino, nas décadas de 1940 a 1960. A Escola Técnica de Goiânia é o campo empírico de investigação. À época, não se exigia qualquer formação pedagógica dos professores que atuavam no ensino profissional. De modo geral, eram egressos do ensino técnico e/ou bacharéis em diferentes áreas do conhecimento. Destaca-se a atuação da Comissão Brasileira-Americana de Ensino Industrial na formação desses docentes que demarcou uma identidade profissional produtivista e americanista.
\end{abstract}

Palavras-chave: formação docente; educação profissional; CBAI; ideologia; produtividade.

\begin{abstract}
The aim of this study is to analyze one of the productive marks in the formation of teachers of professional education to understand the ideology that underpinned the teaching work in this modality of teaching in the 1940s to 1960s. The Goiânia Technical School is the Field of research. At the time, no pedagogical formation was required of teachers who worked in professional education. In general, they were graduates of technical education and/or bachelors in different areas of knowledge. The work of the Brazilian-American Commission of Industrial Education in the training of these professors that demarcates a productivist and Americanist professional identity is highlighted.
\end{abstract}

Keywords: teacher training; professional education; CBAI; ideology; productivity.

Resumen: Se pretende, en este trabajo, analizar uno de marcos estructurantes de la productividad en la formación de profesores de la educación profesional, para entender la ideología que ha fundamentado la labor docente en esta modalidad de educación, en las décadas de 1940 a 1960. La Escuela Técnica de Goiânia es el campo empírico de investigación. En aquel momento, no se exigía 
cualquier formación pedagógica de los profesores que actuaban en la enseñanza profesional. En general, eran graduados de la enseñanza técnica y / o licenciados en diferentes áreas del conocimiento. Es de destacar la actuación de la Comisión Brasileña Americana de Enseñanza Industrial en la formación de esos profesores que ha demarcado una identidad profesional productivista y americanista.

Palabras clave: formación del profesorado; educación profesional; CBAI; ideología; productividad.

\section{INTRODUÇÃO}

O ano de 2017 se iniciou com a aprovação pelo Senado Federal da convertida em Lei $\mathrm{n}^{\circ} 13.415$ de 16 de fevereiro, que regulamenta a Reforma do Ensino Médio e provocou contundentes mudanças na Lei nº 9.394/1996 (BRASIL, 1996), de Diretrizes e Bases da Educação da Educação Nacional (LDBN). Dentre as várias disposições prescritas por essa legislação, uma das mais criticadas pelos movimentos sociais da área de educação trata-se da inclusão dos incisos IV e $\mathrm{V}$ no art. 61 da LDB, que institui a possibilidade de "profissionais com notório saber reconhecido pelos respectivos sistemas de ensino" ministrarem, no Ensino Técnico e Profissional, conteúdos de áreas afins à sua formação ou experiência profissional, "atestados por titulação específica ou prática de ensino em unidades educacionais da rede pública ou privada ou das corporações privadas em que tenham atuado" (BRASIL, 2017). Esta possibilidade traz novos elementos para o debate acerca da formação dos professores que atuam na educação profissional.

As Diretrizes Curriculares Nacionais para a Educação Profissional Técnica de Nível Médio, instituídas pela Resolução CNE/CEB N. 6/2012,) em seu art. 40, pareciam avançar nesse sentido, ao estabelecerem a necessidade de a formação inicial para a docência nessa modalidade de ensino realizar-se em "cursos de graduação e programas de licenciatura ou outras formas, em consonância com a legislação e com normas específicas definidas pelo Conselho Nacional de Educação" (BRASIL, 2012, grifo dos autores).

Essa Resolução, por um lado, indicava a exigência dos cursos de licenciatura para a atuação docente na educação profissional, e por outro, apontava que essa formação dar-se-ia por "outras formas" previstas em lei. Assim, o reconhecimento de "notório saber" por parte dos sistemas de ensino vem preencher uma lacuna deixada pelas DCN para a Educação Profissional Técnica de Nível Médio, ao mesmo tempo em que reforça a tendência presente desde o início da implantação da educação profissional no Brasil: a não exigência de formação pedagógica para os docentes que nela atuam. Contraditoriamente, nota-se a recorrência de 
iniciativas que buscam preencher essa ausência de formação/certificação docente, com vistas a promover a eficiência e a produtividade do professor da educação profissional e do trabalhador por ela formado.

Analisa-se aqui a formação dos professores da Escola Técnica de Goiânia $(E T G)^{1}$ nas suas primeiras décadas de funcionamento e a importância da a Comissão Brasileira-Americana de Ensino Industrial (CBAI), instalada em 1946 e extinta em 1962, na formação e atuação docente na educação profissional, nesse período.

As modificações na legislação educacional promovidas pelo Estado Novo (1937-1945) induziram à reorganização administrativa e pedagógica das escolas profissionais. Além de se adequar a essa legislação, a ETG precisava assumir papel coerente com a relevância da Região Centro-Oeste no emergente processo de industrialização, momento histórico de passagem do modelo agrário-exportador para o modelo de substituição das importações. O Brasil desenvolvimentista necessitava expandir a área produtora de matérias-primas para a indústria em ascensão e ampliar seu mercado interno consumidor. Diante disso, o Governo Vargas empreendeu a 'Marcha para o Oeste', a fim de integrar novas fronteiras agrícolas. Conforme Carvalho (2012), consolidou-se, nesse período, o discurso da vocação agrícola da Região Centro-Oeste. A mudança da capital do Estado para Goiânia favoreceu esse processo. A efervescência do momento político e econômico marcou a trajetória da ETG.

Tal conjuntura circunstancia a formulação do problema de pesquisa: quem eram os professores da Escola Técnica de Goiânia, em suas primeiras décadas, e qual a importância da CBAI na formação de professores? A abordagem epistemológica orientadora da investigação que subsidia a elaboração deste artigo é o materialismo histórico dialético. Foi escolhida com o intuito de apreender as contradições que permearam a formação e atuação docente nas primeiras décadas da ETG. O caráter científico do conhecimento histórico consiste na essência dessa abordagem teórica, que se fundamenta na análise das estruturas econômicas e na dinâmica das sociedades humanas com o objetivo de orientar a práxis social (MARX; ENGELS, 2005; FRIGOTTO, 1997).

Os dados do campo empírico foram obtidos mediante análise documental de fontes primárias e de entrevistas com oito ex-alunos da ETG frequentes de 1943 a 1958. Deles, contam dois egressos da primeira turma; uma, da segunda; um, da terceira; uma, da sétima; um, da nona e dois, da décima terceira. Seis deles

\footnotetext{
1 A ETG, hoje, Instituto Federal de Educação, Ciência e Tecnologia de Goiás (IFG) surgiu na Cidade de Goiás, em 1909, como Escola de Aprendizes Artífices (EAA). Lá, funcionou até 1941, quando foi transferida para Goiânia, devido à mudança da capital do Estado. Em 1942, foi instalada no centro da nova capital, em prédio próprio e ganhou o nome "Escola Técnica de Goiânia" (SÁ, 2014).
} 
concluíram apenas o curso industrial básico (que correspondia ao ciclo ginasial). Dois cursaram o industrial básico e o técnico (que correspondia ao colegial). Esses foram, posteriormente, professores e gestores da instituição e contribuíram para analisar a formação e o trabalho docente no ensino técnico, nessa época. Um dos ex-alunos estudou na antiga EAA, na Cidade de Goiás e rememorou durante a entrevista como vivenciou o processo de transferência da escola para a nova capital.

As entrevistas forneceram contribuições importantes, elucidando aspectos da investigação que os documentos primários e a literatura não evidenciavam. Tem-se clareza de que não é possível captar o fato histórico, em si, por meio de entrevistas, mas a memória construída sobre ele. Compreender o significado atribuído ao processo histórico pelas pessoas que o vivenciaram consiste, pois, em uma importante tarefa para construir a memória do IFG e dos primeiros alunos e mestres da instituição. $\mathrm{Na}$ pesquisa, procurou-se apreender qual era a formação dos professores e alguns aspectos relevantes do trabalho docente no ensino técnico.

A lógica argumentativa deste trabalho compreende inicialmente a abordagem da formação dos professores nos primeiros anos da Escola Técnica de Goiânia, com o objetivo de elucidar quem eram os docentes que ministravam as disciplinas de cultura geral e que atuavam nas oficinas e qual era sua formação. $\mathrm{Na}$ sequência, discute-se a contribuição da CBAI na formação docente para o ensino técnico nos anos 1950, no que se refere à eficiência e a produtividade voltadas para o mercado. E se analisa a formação docente para o ensino técnico nos anos 1950 como terreno fértil para a ideologia do nacionalismo desenvolvimentista

\section{A FORMAÇÃO DOS PROFESSORES NOS PRIMEIROS ANOS DA ESCOLA TÉCNICA DE GOIÂNIA}

De acordo com os depoimentos dos egressos, quando a escola começou a funcionar, faltavam muitos recursos materiais e humanos, mas isso não impediu o início das aulas, como relatou um sujeito da pesquisa: [...] funcionou, assim mesmo [...] tinha muitos cursos que eram pra ensinar, mas, não tinha professor (J.O.F.).

Essa falta de professores dificultou a instalação de algumas oficinas (ou cursos), que tiveram seu início adiado, como destacou J.O.F.: [...] a alfaiataria não tinha professores, não funcionou no primeiro ano. Silva (2006) assinala o empenho das pessoas que trabalhavam na instituição, com vistas a oferecer o melhor ensino possível, determinado pelas condições existentes nesse primeiro período de implantação da ETG, em Goiânia. 
Em fevereiro, mesmo com a falta de muitos professores, tanto na área de educação geral quanto na formação profissional, tiveram início as aulas. Para minorar um pouco esse difícil quadro, se transferiu da antiga Escola de Aprendizes Artífices da cidade de Goiás, a professora de português, [...] de geografia e história [...] e de geometria e desenho. Porém, ainda faltavam professores para muitas outras matérias e era muito difícil nomeá-los, porque dependia de ato do Governo Federal, instalado no Rio de Janeiro. Durante todo o primeiro ano de funcionamento da Escola, muitas vezes, o Prof. Lisbôa ${ }^{2}$ reunia todos os alunos no auditório e ministrava aulas de matemática e/ou ciências físicas e naturais para as mais diversas turmas, reunidas num único salão (SILVA, 2006, p. 112-113).

Para ingressar no Ensino Básico (primeiro ciclo do ensino industrial) da ETG, o candidato precisava ter cursado pelo menos dois anos do ensino primário e ser aprovado em um exame de admissão. Já para ingressar nos cursos técnicos (segundo ciclo do ensino industrial), o aluno deveria ter concluído o primeiro ciclo (ou equivalente) e prestar exame vestibular ${ }^{3}$.

$\mathrm{Na}$ antiga EAA não se requeriam conhecimentos prévios, nem mesmo de leitura e escrita. Segundo Cunha (2005), essa mudança demonstra alteração das finalidades e da filosofia da instituição, para atender às demandas do momento histórico, que necessitava de uma força de trabalho mais qualificada. Na EAA, a escolaridade obtida era o primário. Já a ETG ministrava ensino profissional equiparado ao nível médio.

De acordo com os depoimentos dos entrevistados, nos primeiros anos de funcionamento da ETG, atuavam professores com formação bastante diferenciada. Alguns professores das primeiras turmas vieram da EAA, com a transferência da Escola para Goiânia. Destes, a mais citada pelos entrevistados foi a Professora Laura, que ministrava desenho e possuía formação em Odontologia.

Os professores que lecionavam as disciplinas de cultura geral não possuíam formação para a docência. Quase todos eram bacharéis em diferentes áreas do conhecimento. Compunham o corpo docente da ETG destacados representantes dos intelectuais goianos e goianienses, como os professores Bernardo Élis (bacharel em direito e escritor), Domingos Félix (bacharel em direito e escritor), Belkis Spencieri (bacharel em música), Jorge Félix de Souza (arquiteto), Hernning Gustav Ritter (arquiteto e artista plástico), dentre outros. Seguem trechos da fala de uma entrevistada sobre esses renomados mestres:

Professor Antônio Manoel de Oliveira Lisboa, natural da Cidade de Goiás, antiga capital do Estado, nasceu em 16 de setembro de 1892. Foi o primeiro diretor da Escola Técnica de Goiânia (ETG), cargo que ocupou de 17/07/ 1941 até 08/08/1956 (ETG, 1978).

3 Estes exames foram instituídos como forma de selecionar os candidatos considerados aptos ao ensino técnico industrial, que se equiparou ao ensino secundário e, nesse processo, assimilou aspectos seletivos e excludentes que caracterizavam esse nível de ensino no Brasil, na época. Esse termo está presente, inclusive, nas fichas dos alunos da ETG, que foram analisadas e sistematizadas para compor o corpo empírico desta pesquisa. 
O Bernardo Élis era professor de História e o Domingos Félix era de Português. O José Nascimento era, também, de Português [...] As três professoras de desenho eram a Laura, a Julieta e a Adélia. E tinha aula de música com a Nair de Moraes. [...] Todos eles, os professores, tinham formação superior. A Nair de Morais, a Edinéia, tinham curso superior. Elas eram pianistas. E o Domingos Felix, que era o professor de português, o Renato era professor de ginástica e o José Alves, também, era da ginástica. Agora, na área profissional, eu acho que todos eram formados, assim, nas próprias escolas, nas oficinas (O.A.).

Todos os entrevistados enalteciam a competência dos professores e orgulham-se do processo de aprendizagem com eminentes profissionais, intelectuais e artistas da nova capital, como se observa no depoimento a seguir:

Não me esqueço do professor Jorge Félix de Souza, que foi quem projetou, aqui, o Cine Teatro Goiânia, a igreja Coração de Maria, a Catedral Metropolitana de Goiânia. Era um autodidata, assim, fantástico e escritor. Formado pela Escola Nacional de Arquitetura, no Rio de Janeiro (MDD)

Embora com formação superior e reconhecido saber em sua área de atuação, esses professores das disciplinas de cultura geral não eram preparados para atuar no ensino nem na educação profissional, como acontecia, em todo território nacional. Já os docentes que ministravam as disciplinas técnicas ou "das oficinas" eram, muitas vezes, profissionais da área que possuíam relevante saber prático, dos quais não era exigida certificação. Um dos ex-alunos afirmou que a maioria desses profissionais mais antigos era proveniente da Cidade de Goiás e os mais novos, ex-alunos da própria ETG ou de outras escolas técnicas do país, como se lê no trecho da entrevista:

Já os professores das oficinas [...] eram mais técnicos. Na minha época, por exemplo, já eram os ex-alunos da Escola Técnica que ensinavam nas oficinas. Já eram as pessoas que terminaram o curso Industrial Básico e que, depois, fizeram o curso Técnico, a maioria fora. Iam para o Rio de Janeiro, iam pro Paraná, pra Curitiba, terminavam seus cursos lá e vinham dar aula, aqui [...] E, tinham aqueles professores antigos, que vieram de "Goiás Velho". Então, não eram pessoas letradas, nem nada. Eram bons artífices, ensinavam, e até possuíam alguma didática pra ensinar a profissão, mas, eram pessoas, vamos dizer assim, sem uma cultura didática, sabe? Não tinham formação universitária, essa coisa... (MDD)

Dois dos entrevistados, logo que concluíram seus cursos na ETG, tornaram-se professores da instituição, no início da década de 1950. Seu relato reforça a ideia de que, nos anos iniciais de funcionamento da ETG, alguns docentes iniciavam sua atividade do magistério possuindo apenas formação técnica de nível médio. 
Oliveira e Leszczynski (2009) afirmam que, na década de 1940, grande parte da população adulta do Brasil era analfabeta. Nessas circunstancias, recrutar professores para o ensino industrial era um grande desafio. A maioria dos mestres das oficinas eram provenientes das indústrias, que surgiam principalmente nos grandes centros de todo o país, e não possuíam sequer a formação básica suficiente para o cargo de professor. Essa situação fazia com que a formação de docente para atuar nessa área fosse uma preocupação dos dirigentes nacionais.

\section{Professores e alunos da oficina de mecânica de máquinas (1943) Primeira turma da ETG}

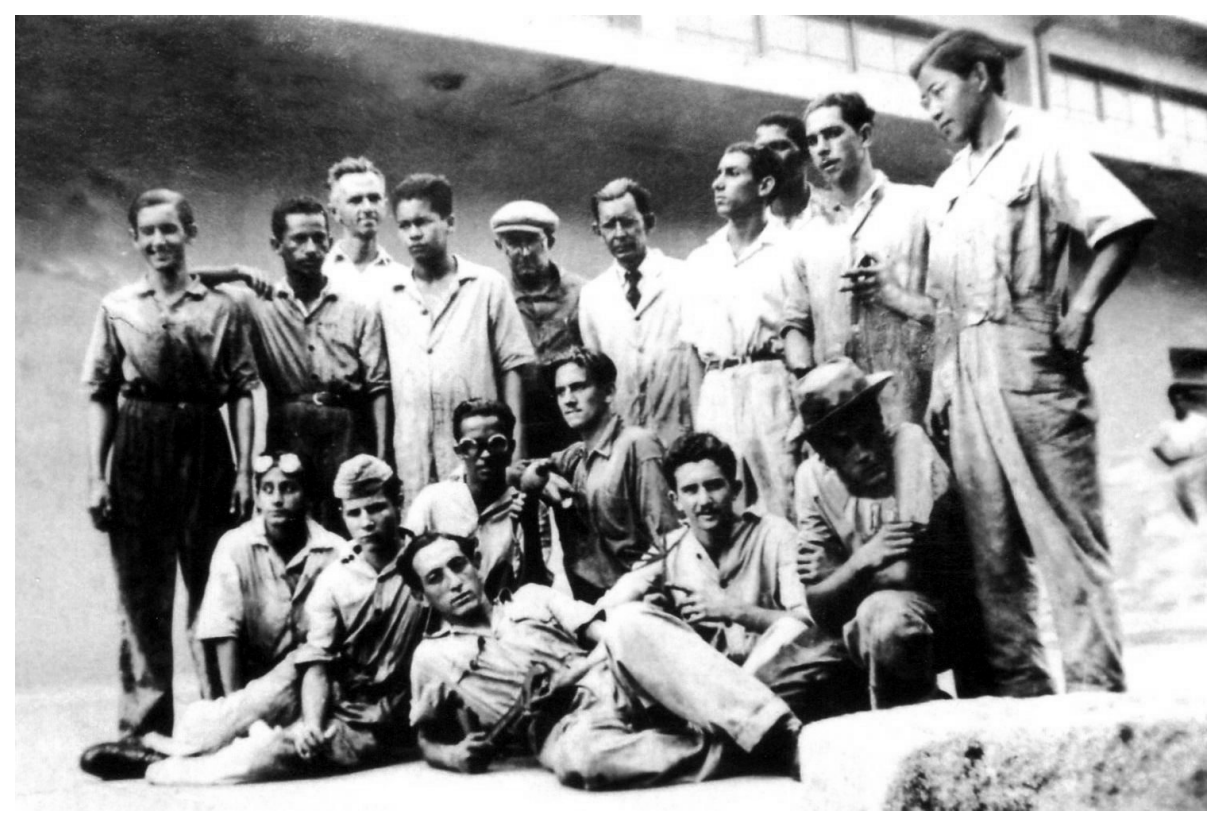

Fonte: Acervo Etegeanos 50 anos.

\section{A CBAI E A FORMAÇÃO DOCENTE PARA O ENSINO TÉCNICO NOS ANOS 1950: PROMOVENDO A EFICIÊNCIA E A PRODUTIVIDADE}

Um dos egressos entrevistados relatou que, na década de 1950, o governo federal desenvolveu um programa de formação de professores para as escolas técnicas do país. Durante as férias escolares de fim de ano no período de 1951 a 1954, um grupo de professores se deslocava para a capital federal (Rio de Janeiro), 
onde permanecia de janeiro a março fazendo cursos de aperfeiçoamento e aprofundamento pedagógico e metodológico de ensino na CBAI. No depoimento constata-se que

Foi criado lá no Rio de Janeiro, ainda naquele tempo, a CBAI - Comissão Brasileiro-Americana de Ensino Industrial. Essa comissão dava a parte pedagógica para o cidadão. Você formou em engenharia, você é professor? Não. Você tem conhecimento pra ser professor, você tem conteúdo pra ser um professor, mas a parte pedagógica, pouquíssima coisa. Então, essa comissão era pra isso. Nós tínhamos professores brasileiros, americanos, suíços. E esses professores eram gente de alto nível cultural e na área didático-pedagógica [...] eu já fui convidado, pra ir para o Rio, para fazer esse curso. Esse curso era intensivo, era pesadíssimo. Então, você pegava de segunda a sábado no batente, o dia inteiro, 8 horas por dia, 8 horas de serviço, por dia de curso. E levava serviço pra ficar até meia-noite, uma hora, fazendo, porque, no outro dia, você tinha que dar uma aula, você tinha que criticar um trabalho. Tinha um punhado de coisas que você fazia, pra provar que você estudou à noite. Então, eram dois meses assim. Isso eu fiz quatro anos [19511954] (H.N.).

A CBAI mantinha um programa ${ }^{4}$ por meio de convênios entre os governos do Brasil e Estados Unidos, que se propunha a desenvolver ações de capacitação, recrutamento de professores, diretores, orientadores e supervisores do ensino técnico dos dois países. Nesse convênio, estavam previstos além de cursos de treinamento, a aquisição e produção de equipamentos, textos, livros, revistas e outros materiais didáticos (OLIVEIRA; LESZCZYNSKI, 2009).

O ex-aluno que, posteriormente, foi professor e diretor da instituição, em seu depoimento, transcrito a seguir, avalia que a formação oferecida pela CBAI contribuiu para melhorar o conhecimento científico, técnico e pedagógico dos professores das instituições profissionais.

Melhorou demais pra todos nós. Eu, já no primeiro ano, já cheguei e comecei a elaborar apostilas, comecei a elaborar provas com mais conhecimento pra poder obter do aluno um melhor aprendizado e ver se ele realmente aprendeu, porque a gente se preocupava demais [...] Todos nós passamos a ter outra visão do que é ensino, do que é aprendizagem, do que é motivação [...] Isso foi extraordinário [...] Eu notei uma promoção, uma elevação muito grande no nível do quadro docente,

Esse programa resultou de um acordo bilateral entre Brasil e Estados Unidos, que surgiu como ideia inicial na I Conferência de Ministros e Diretores de Educação das Repúblicas Americanas realizado em Havana, de 25 de setembro a 04 de outubro de 1943 (OLIVEIRA; LESZCZYNSKI, 2009). 
quando eu voltei para dirigir a escola [...] Vi e posso dizer que mudamos de água pra vinho, porque nos anos anteriores, eram engenheiros, arquitetos, advogados lecionando matemática, e tudo... Advogados lecionando português, odontóloga lecionando geometria plana, essa coisa... Quer dizer, eles podiam conhecer a disciplina que estavam lecionando, mas não tinham nenhuma formação pedagógica (H.N.).

A avaliação desse entrevistado corrobora os resultados da pesquisa realizada por Oliveira e Leszczynski (2009). As autoras defendem a ideia que, apesar de todas as críticas empreendidas aos acordos bilaterais e à influência de organismos internacionais na educação brasileira, a CBAI contribuiu de forma expressiva para a organização e o funcionamento de ensino industrial do país. Consoante as referidas pesquisadoras, a CBAI colaborou para o desenvolvimento de uma cultura na área industrial, por intermédio de cursos e editoração de textos que difundiram métodos, técnicas de ensino e ideias que pretendiam orientar o trabalho formativo nas escolas industriais.

Um dos métodos trazidos pelos norte-americanos, que se tornou mais conhecido e adotado, tanto nas escolas industriais, quanto no SENAI e nos programas de instrução em serviço nas empresas, foi o Training Wihthin Industry (TWI), que objetivava obter maior eficiência e produtividade do trabalhador, por meio das séries metódicas. Segundo Batista (2015), o TWI foi desenvolvido, após a primeira guerra mundial, por um grupo de empresários norte-americanos, com o objetivo de capacitar de maneira rápida e eficaz os operários que ocuparam o lugar daqueles mais experientes, deslocados para as frentes de batalha. Esse método foi criado para o treinamento em serviço nas fábricas, mas foi posteriormente adotado nas escolas profissionalizantes dos Estado Unidos e transplantados para o Brasil pela CBAI no período de rápida industrialização ocorrido entre as décadas de 1930 a 1960.

Esse método foi adaptado às características das escolas profissionais brasileiras pelo engenheiro Roberto Mange ${ }^{5}$ que adotou o nome de Série Metódica Ocupacional (SMO). A justificativa de Mange para sua adaptação foi o fato de considerá-lo extremamente limitado e empírico, destituído de bases científicas. Para ele, a linguagem do TWI era eminentemente voltada para as oficinas e pouco acadêmica. Sua adoção nas escolas técnicas requeria uma metodologia mais abrangente e científica (BATISTA, 2015).

\footnotetext{
5 Roberto Mange foi o primeiro Diretor do Departamento Regional de São Paulo do SENAI. De acordo com Cunha (2005), o engenheiro mecânico, de origem suíça, diplomou-se na Escola Politécnica de Zurich, em 1910, e chegou ao Brasil em 1913, contratado pela Escola Politécnica de São Paulo. Ele foi importante líder do ensino profissional brasileiro nas décadas de 1920 a 1950
} 
Müller (2009), pesquisadora que analisou esse método nas escolas do SENAI, esclarece que o processo era desenvolvido basicamente da seguinte forma:

\begin{abstract}
Os aprendizes deveriam conhecer, através de aula expositiva, os processos de elaboração de cada tarefa, passando depois a analisar uma série de descrições escritas e desenhadas sobre o trabalho a ser realizado. Depois disso, realizavam exercícios teóricos sobre o tema, organizados de forma sistemática e por ordem crescente de dificuldade. Só depois de entender a teoria e as ferramentas a serem utilizadas na realização da tarefa é que os aprendizes eram levados às oficinas, em grupos, para observar um mestre na execução da tarefa, devendo repeti-la sob sua supervisão e depois sozinhos, cada um em sua bancada e a seu ritmo (p, 220).
\end{abstract}

Um dos egressos da ETG se referiu a essa metodologia assim:

Primeiro você estuda nos livros as técnicas e depois vai pra oficina realizar o que aprendeu e praticar. Era essa a rotina na nossa oficina. Desenvolver os conhecimentos técnicos e a prática na oficina sobre a composição, manual e mecânica, a impressão, a encadernação e o acabamento da encadernação (G.A.L.V.).

Oliveira e Leszczynski (2009) afirmam que as orientações da CBAI se fundamentavam nos princípios da administração científica e visavam a convencer os docentes e gestores do ensino industrial da necessidade de se obter, por meio da padronização de procedimentos, o máximo de eficiência com o mínimo de perdas, tanto de tempo quanto de materiais. Para tanto, os docentes deveriam implementar tais princípios em suas oficinas e salas de aula, para capacitar seus alunos a se tornarem cidadãos produtivos e eficientes, que pudessem contribuir para o desenvolvimento econômico do país.

O egresso H. N. declarou que esses princípios e métodos foram utilizados nas escolas industriais e, dentre elas, na Escola Técnica de Goiânia, após a oportunidade que tiveram seus professores e gestores de participar dos programas de treinamento da CBAI. Ele analisa sua importância no ensino técnico:

A CBAI se preocupava em dar ao professor uma condição maior pra ele enxergar o processo educacional... não era somente o processo do como fazer isso ou aquilo. Era diferente. Você devia escrever, devia propor um sistema de aprendizado. Isto sim, estava incluído no aprendizado da CBAI. Como é que eu vou ministrar um curso de mecânica... por exemplo de torneiro, sem ter uma sequência lógica de tudo que é operacional naquilo? Sempre começando do mais simples, para o mais difícil. 
Eu preciso ter isso sempre muito bem concatenado. Eu preciso ter desenhos disso, pra passar para o meu aluno ver. Eu preciso estar com a parte tecnológica disso muito bem, porque uma coisa é ensinar você desbastar num torno, outra coisa é você entender como aquele torno pode produzir mais, e como você vai ter menos desgaste com a máquina e com a ferramenta... que aí é a parte tecnológica. Por exemplo, eu chego aí e vejo você trabalhando numa máquina e sei se você é um bom profissional ou não.

Nesse período, a base do desenvolvimento brasileiro era a industrialização em substituição às importações, dificultadas pelas duas Guerras Mundiais. Para que esse processo se efetivasse, era imprescindível a formação de um grande contingente de operários qualificados para atuarem nas indústrias em processo de constituição, bem como nos serviços de infraestrutura para sua implantação e consolidação.

Batista (2015) e Cunha (2005) enfatizam a relevância da educação no projeto da burguesia industrial que estava se consolidando como classe dominante. Era fundamental educar e capacitar o trabalhador para as demandas da nova realidade econômica do país. A implantação desse projeto pretendia atender não só aos interesses nacionais; daí, a importância de se compreenderem os acordos multilaterais efetivados nesses períodos.

Destaca-se que a conjuntura dos anos 1940 a 1960 foi marcada pelo processo de industrialização impulsionado a partir da Revolução de 1930 e pela construção da hegemonia norte-americana no Continente, após a Segunda Guerra Mundial. Nessa guerra, a declaração de apoio aos países aliados contra o Eixo representou um marco na inflexão da política externa brasileira. O mundo, à época, dividia-se em dois campos ideológicos: de um lado, as nações que lutavam pela supremacia da democracia e, de outro, os defensores dos regimes totalitários (ARENDT, 2004, CUNHA; FALCÃO, 2009; OLIVEIRA; LESZCZYNSKI, 2009).

Para Ciavatta (2013), a CBAI possibilitou a constituição de um ambiente educacional favorável à presença das ideias norte-americanas no Brasil, num momento em que o país caminhava para uma progressiva associação com o capital internacional. A autora ressalta, ainda, que a partir dessa época, o Estado se torna o mediador dos conflitos entre o capital e o trabalho, valendo-se da legislação social consubstanciada na Consolidação das Leis Trabalhistas (CLT), que visava a controlar a reprodução da força de trabalho. A autora ressalta a importância do Estado brasileiro na criação de uma infraestrutura legal e burocrática necessária à reprodução do sistema econômico.

$O$ processo de industrialização era considerado decisivo para o desenvolvimento econômico nacional e provocou impacto na organização e consolidação do ensino industrial. Uma nova racionalidade na educação, 
configurada por uma vertente de pensamento funcional e pragmático, impôsse como solução para os problemas da formação e disciplinamento da força de trabalho para a indústria, de forma a adequá-la a organização fabril. "A preparação profissional, nos seus elementos técnicos e morais, é, agora, apresentada como recurso para o aumento da produtividade do trabalhador" (CIAVATTA, 2013, p. 501).

Embora na educação ainda predominasse um discurso humanista, a escola foi instigada a responsabilizar-se pelo aumento da produtividade do trabalho e, consequentemente, da riqueza nacional. No campo educacional, as demandas do capital passaram a ser universalizadas como se fossem necessidades do operariado, quais sejam, a defesa da produtividade do trabalho e do trabalhador. Coube ao Estado assumir a tarefa de organizar e implementar o ensino industrial, conciliando a formação humana e a preparação para o trabalho na indústria.

Ciavatta (2013) considera essa conciliação uma tarefa difícil em face do confronto entre duas lógicas distintas e contraditórias: a da produção capitalista e a da educação. A primeira tem seu fundamento no lucro, na exploração do trabalho, no tempo breve em que a atividade laboral deve ser realizada, no corte de custos, no incremento da produtividade, na competitividade, na mercantilização da produção. Por sua vez, a lógica da educação se assenta na formação humana para a emancipação das amarras da opressão, para a cidadania e para a participação construtiva. Para tanto, a educação deve orientar-se pelo diálogo, pela discussão, pela socialização de conhecimentos, o que demanda um tempo médio e longo de aprendizado e desenvolvimento, pois implica o reconhecimento das necessidades do outro e o respeito a sua individualidade.

\section{A FORMAÇÃO DOCENTE PARA O ENSINO TÉCNICO NOS ANOS 1950 E A IDEOLOGIA AMERICANISTA E DESENVOLVIMENTISTA}

Cunha e Falcão (2009) afirmam que a CBAI promoveu cursos, visitas técnicas e um amplo programa editorial que atingiu, prioritariamente, professores e diretores das escolas industriais da rede federal, constituindo-se em eficaz 
difusor de métodos de treinamento segundo os princípios tayloristas ${ }^{6}$. Os autores agrupam as atividades da Comissão em quatro eixos: coordenação e difusão, cursos, publicações e pedagogia/ideologia.

A primeira e a mais persistente das ações da CBAI foi, segundo os autores, a reunião dos diretores das escolas da rede federal de ensino industrial no Rio de Janeiro, a fim de assistir palestras de educadores norte-americanos e brasileiros sobre temas administrativos e pedagógicos. Discutiam-se aspectos ligados à gestão das escolas e temas como a importância do levantamento das necessidades de qualificação da força de trabalho em cada local.

Os autores também registram que os professores e gestores das escolas industriais tiveram oportunidade de frequentar diversos cursos e participar de estágios, tanto em escolas como em indústrias, no país e nos Estados Unidos, no período de 1947 a 1962. Os cursos abordavam especialidades industriais e artesanais e aspectos acerca do aperfeiçoamento e controle do trabalho dos professores, de normas de organização do ensino industrial, de técnicas de ensino, de rendimento escolar e suas medidas, programas escolares e problemas de administração escolar. Oliveira e Leszczynski (2009) destacam que os conteúdos dos cursos oferecidos pela CBAI referiam-se tanto aos saberes técnicos quanto aos conhecimentos pedagógicos, que, de acordo com as autoras, faziam parte de todos os treinamentos ministrados.

De 1947 a 1961, a CBAI publicou um boletim que atingiu 150 números, 124 livros e folhetos que versavam a respeito da cultura técnica até a administração do ensino e legislação educacional. No Boletim ${ }^{7}$, além de textos de técnicos estrangeiros e nacionais, registra-se a presença de nomes destacados da educação brasileira como Anísio Teixeira, Fernando Azevedo e Lourenço Filho. Os livros e folhetos foram organizados pela própria entidade em séries: 11 de cultura geral, 22 de educação industrial, 28 de cultura técnica, 19 de didática para oficinas.

6 O taylorismo é uma concepção de gestão e hierarquização da produção baseada em um método científico de organização do trabalho, idealizada por Frederick W. Taylor (1856-1915). Engenheiro mecânico norte-americano, que introduziu o conceito de Administração Científica, que revolucionou o sistema produtivo no começo do século XX, criando a base sobre a qual se desenvolveu a atual Teoria Geral da Administração. A concepção de Taylor reforça e justifica teoricamente a fragmentação das atividades laborais na indústria e a separação do trabalho manual e intelectual. Este modelo de organização hierarquizada e sistematizada exige que o tempo de produção seja rigidamente controlado e fiscalizado (GARCIA, 2012).

$7 \quad$ O Boletim era publicação mensal com o objetivo de difundir as atividades realizadas pela Comissão e de contribuir para a formação de professores, diretores e orientadores educacionais das escolas industriais. Essa publicação consiste em importante fonte de consulta para os pesquisadores da história do ensino profissional no Brasil. O Boletim era distribuído em todas as escolas industriais do país, o que possibilitou a divulgação das atividades e da ideologia da CBAI nacionalmente. (CUNHA; FALCÃO, 2009; OLIVEIRA; LESZCZYNSKI, 2009.). 
Além desses, existiram 44 títulos publicados fora das séries. A Comissão, também traduziu obras brasileiras para o inglês, a fim de divulgá-las nos Estados Unidos (CUNHA; FALCÃO, 2009).

Os autores destacam alguns elementos mais explícitos da ideologia difundida pela CBAI: o americanismo, o industrialismo e o desenvolvimentismo. Essa forte presença ideológica encontra-se no editorial do primeiro número do Boletim, publicado em janeiro de 1947.

Desde 1940, como uma fase de cooperação com um aliado indispensável na luta mundial para conseguir e manter a liberdade, representantes dos Estados Unidos têm trabalhado em conjunto com líderes brasileiros e de outras nações latinoamericanas no desenvolvimento de diversos aspectos do ensino, principalmente os que se referem à saúde, eficiência da produção e bem-estar dos povos (BOLETIM N. 1 apud CUNHA; FALCÃO, 2009, p. 163).

De acordo com os autores, as publicações do CBAI propagavam a ideologia do industrialismo, em sua forma mais ingênua, reforçando sua importância para o desenvolvimento do país. A máquina era apresentada como força revolucionária e invenção organizadora do mundo moderno.

Quanto ao campo educacional, Cunha e Falcão (2009) afirmam que os editoriais do Boletim manifestavam um "otimismo pedagógico" do professor era evocada como o missionário abnegado. Os autores reconhecem que a CBAI demonstrava, em suas ações e publicações, uma preocupação com a formação docente, a fim de evitar a improvisação, ao contrário do que historicamente prevaleceu no Brasil.

As técnicas visuais eram muito incentivadas, por meio, por exemplo, da distribuição de filmes $16 \mathrm{~mm}$ para as escolas industriais. O Boletim N. 1, de 1951 (apud CUNHA; FALCÃO, 2009) informava que a CBAI dispunha de um acervo de 71 filmes sobre o trabalho nas oficinas, sendo 34 sobre tecnologia e 45 de cultura geral.

8 De acordo com Nagle (2001), nos anos 1920, época de significativa transformação cultural no país, o entusiasmo pela educação, que marcou as duas primeiras décadas da República. Foi contemporâneo do movimento: o otimismo pedagógico, que evidenciava a influência estadunidense, no Brasil, no campo pedagógico. De acordo com Brzezinski (1987), o entusiasmo pela educação era decorrente da crença nas possibilidades de a educação solucionar problemas fora de seu âmbito. 
Para perceber como a ideologia desenvolvimentista da época fazia parte do pensamento dos estudantes da Escola Técnica de Goiânia, cita-se a seguir um texto publicado no O ETG, N. 5, Ano II, do jornal "O ETG", redigido pelo estudante Waldomiro Borges, da quarta série da primeira turma de artífices formados pela instituição:

\section{A Primeira Turma de Diplomandos da Escola Técnica de Goiânia}

Findas as férias em 20 de fevereiro, reiniciamos nossos estudos. Cá estamos nós, os quartanistas, ansiosos por ver chegar o fim do ano. Daqui lá teremos de nos esforçar, a-fim-de recuperar parte do tempo perdido em virtude de fatores estranhos à nossa vontade. A turma de quartanistas é de 50 alunos, os primeiros a concluírem o curso. É isso um orgulho, muito embora, saibamos que lá fora nos esperam as incertezas da vida profissional; [...\} Entretanto, "agir com inteligência e bondade" é o lema que guiará todo aquele que quer vencer na vida, onde os obstáculos são sempre numerosos. [...] O certo, porém, é que esta turma não se deixará levar por fraquezas, mas se guiará pela força de vontade. [...] O destino está em cada um de nós, como naquela sentença: "Faz a tua parte, que te ajudarei". Avante! Pois, aproxima-se a hora em que devemos empregar o máximo esforço para algum dia desfrutar dos benefícios e honras que se devem aos vencedores. ... Nada de enfraquecimento e tibieza: o Curso Industrial oferece mil oportunidades, e a nós, portadores dele, compete uma grande tarefa neste país onde tanta coisa há que construir no campo de nossa atividade (O ETG, 1946, p.1).

Esses textos demonstram como a ideologia desenvolvimentista era inculcada nos estudantes e qual o papel a eles destinado: trabalhadores responsáveis, esforçados e dedicados a construir a grandeza da pátria. A instrução técnica era compreendida como grande oportunidade de "vencer na vida", oferecida aos jovens de famílias de baixa renda. Por isso, eles não poderiam deixar-se vencer pelos obstáculos, mas retribuir, com seu trabalho competente, para o desenvolvimento do país (SÁ, 2014).

Um dos egressos entrevistados demonstrou perceber a influência da ideologia americanista na formação do orientador educacional que atuava na ETG e tinha sido enviado da Capital Federal para a Escola, como se depreende de sua fala a seguir:

9 O Jornal "O ETG" divulgava os acontecimentos e as ideias do corpo discente e docente da Escola Técnica de Goiânia. Este veículo de comunicação, criado em 1945, era organizado e escrito pelos alunos e professores da Escola, composto e impresso na sua oficina de Tipografia e Encadernação. Nesta pesquisa, pudemos consultar três números desse jornal. O Jornal de $\mathrm{N}^{\circ} 1$, Ano I; a edição ${ }^{\circ}$. 03, p. 01, ano 01, nov./dez. 1945 e o No 5, Ano II, publicado em maio de 1946 (ETG, 1945; 1946). 
Quando eu entrei na escola, já existia uma figura nova, um orientador educacional. Ele foi enviado do Rio de Janeiro pra Goiânia, professor Walter [...] O professor Walter como orientador educacional, certamente, pela existência de uma política industrial, depois da Segunda Guerra Mundial, com aqueles acordos culturais e com a aproximação do governo brasileiro do governo norte-americano e aquele alinhamento ideológico e por ter a política educacional recebido influência direta dos estadunidenses, ele demonstrava uma atitude de simpatia em relação aos norteamericanos (G.A.L.V.).

Apesar do evidente alinhamento ideológico ao americanismo e ao industrialismo desenvolvimentista, a ETG não fazia censura ideológica e tampouco excluía de seu interior aqueles que pensavam diferente, permitindo a presença de professores e alunos com posicionamento político de esquerda e incentivando a participação dos alunos na política estudantil, como se destaca na fala do mesmo egresso:

Professor Bernardo Élis, que era o nosso professor de história e geografia do Brasil, um homem que já demonstrava, claramente, uma vinculação com a ideologia da esquerda [...]. Sem usar de proselitismo, pra pessoa ser comunista ou não, ele ficava sempre cotejando os episódios da história do Brasil com os norte-americanos e com outros países da Europa, fazendo uma interpretação dialética materialista, sem, no entanto, botar "caraminholas" na cabeça da gente, né? ... Ele não era um doutrinário sectário, ele fazia a justa posição e o aluno tinha a liberdade de fazer as suas conclusões, as suas inferências, não é? [...] Com a presença do professor Walter, e a sua posição pela direita provocou uma polaridade, e isso foi bom, porque, passamos a ter mais referências na cabeça, né? ... Fortaleceu a ideia daqueles que achavam que o Brasil era um país explorado e subordinado ao capital estrangeiro e pelo imperialismo dos grandes países, ou então, reforçava a convicção daqueles que acreditavam que o caminho que o Brasil estava seguindo deveria ser aquele mesmo, cada vez mais próximo dos ideais norte-americanos, e assim por diante... (G.A.L.V.)

\section{CONSIDERAÇÕES FINAIS}

A pesquisa desvelou que os professores da ETG, nos seus primeiros anos não possuíam, na sua maioria, formação para atuar na docência. Os docentes das áreas técnica eram profissionais, muitas vezes formados pela própria escola e/ou no mundo do trabalho. Já aqueles que atuavam nas disciplinas de cultura geral, embora possuíssem curso superior, eram, geralmente, bacharéis e não dispunham de formação pedagógica. Apesar disso, o trabalho destes "mestres" foi destacado pelos egressos da escola, devido a seu compromisso e sua competência. Eles demonstravam preocupar-se não apenas com a formação profissional do futuro trabalhador, mas também com seu desenvolvimento cultural, ético e político. 
Os depoimentos dos ex-alunos da ETG revelaram a importância da atuação docente no processo de sua formação para o trabalho, para a vida e para o exercício da cidadania. O modelo formativo das escolas profissionais evidencia uma contradição entre a lógica da educação e do capital: a primeira busca a eficiência e o lucro e a segunda, a formação e a emancipação humana. São princípios, valores, práticas e tempos distintos e antagônicos que tornam mais complexa a formação e o trabalho docentes.

Os egressos que foram professores e gestores na ETG destacaram a necessidade de o profissional que atua na formação de outros trabalhadores possuir formação pedagógica específica para essa modalidade de magistério. Nesse sentido, destaca-se a iniciativa de o governo federal oferecer formação específica para os docentes atuantes no ensino industrial, nas décadas de 1940 a 1960, por meio da CBAI. Essa formação promoveu, de acordo, com o relato de um desses dois professores, a melhoria do ensino ministrado na ETG.

A CBAI pode ser considerada um dos marcos fundadores da formação dos docentes do ensino industrial. Os relatos de um dos entrevistados e outras pesquisas analisadas elucidam que as ações e publicações da Comissão contribuíram significativamente para a estruturação do ensino ministrado pelos docentes das escolas profissionais nesse período. Muitos professores puderam frequentar cursos, estágios, realizar viagens de estudo para os Estados Unidos e, com isso, aprofundar seus conhecimentos técnicos, científicos e pedagógicos, ao vivenciar novas experiências e repensando a atuação docente. É importante questionar, porém, qual o modelo de formação docente a que esses professores tinham acesso.

De acordo com Ciavatta (2013), embora a formação dos futuros operários das indústrias aparentasse ser humanista no que dizia respeito à educação técnica e profissional, a Comissão enfatizava a formação da força de trabalho com o propósito de aumentar a produtividade do trabalho e a riqueza da Nação. Esse modelo de formação favoreceu uma intervenção pacífica e consentida na estruturação da educação profissional no Brasil, ao permitir a assimilação do americanismo e do desenvolvimentismo ingênuos, de interesse para a indústria local, que se consolidava e caminhava rumo a uma progressiva associação com o capital internacional.

$\mathrm{Na}$ atualidade, é importante, ainda, refletir sobre o retrocesso que a Lei N. 13.415/2017 impõe à formação de professores do ensino profissional ao admitir que "profissionais com notório saber reconhecido pelos respectivos sistemas de ensino" ministrem, no ensino técnico e profissional, conteúdos de áreas afins à sua formação ou experiência profissional. 
A formação dos professores que atuam na educação profissional passava por um processo de regulamentação e estruturação, principalmente após a aprovação das Diretrizes Curriculares Nacionais para a Educação Profissional Técnica de Nível Médio, instituídas pela Resolução CNE/CEB N. 6/2012, dispositivo legal, que, em seu art. 40, emitia sinais de avanço, à medida que estabeleceu a realização da formação inicial para a docência nessa modalidade de ensino em "cursos de graduação e programas de licenciatura.

Assiste-se à implantação e consolidação, em todo o país, de cursos de licenciatura para o ensino profissional e mestrados profissionais e acadêmicos que têm como objetivo a formação pedagógica desse profissional do magistério. A nova Lei, equivocadamente, retroage ao passado, aos anos 1940, quando o ensino profissional foi estruturado em atendimento às Leis Orgânicas do Ensino e não era exigida formação acadêmica para os professores desses ramos de ensino.

\section{REFERÊNCIAS}

ARENDT, H. As origens do totalitarismo. Trad. Roberto Raposo. Lisboa: Publicações Dom Quixote, 2004.

BATISTA, E. L. Trabalho e educação profissional nas décadas de 1930 e 1940 no Brasil: análise do pensamento e das ações da burguesia industrial a partir do IDORT. Campinas: Autores Associados, 2015.

BRASIL. Congresso Nacional. Lei N. 13.415 de 16 de fevereiro de 2017. Brasília: Diário Oficial, 17 de fevereiro de 2017.

BRASIL. Conselho Nacional de Educação. Resolução CNE/CEB N. 06 de 04 de junho de 2012. Brasília: CNE/MEC, 2012.

BRASIL. Congresso Nacional. Lei N. 9.394 de 20 de dezembro de 1996. Brasília: Diário Oficial, 1996.

BRZEZINSKI, I. A formação do professor para o início da escolarização. Goiânia: Editora da UCG, 1987.

CARVAlHO, M. A. de. Técnico Agrícola: peão melhorado? 2012. 298f. Tese (Doutorado em Educação) - Pontifícia Universidade Católica de Goiás, Goiânia, 2012. 
CIAVATTA, M. Trabalho docente e a produtividade: recuperando marcos fundadores. Educação, Santa Maria, v. 38, n. 3, p. 495-506, set./dez. 2013

CUNHA, L. A. O ensino Profissional na irradiação do industrialismo. $2^{a}$ ed. São Paulo: Editora UNESP; Brasília, DF: FLACSO, 2005.

CUNHA, L. A.; FALCÃO, L. Q.. Ideologia, política e educação: a CBAI (1946/1962). Revista Contemporânea de Educação, Rio de Janeiro, v. 3, p. 148-173, 2009.

FRIGOTTO, G.. O enfoque da dialética materialista histórica na pesquisa educacional. In: FAZENDA, I. (org.) Metodologia da pesquisa educacional. 4 ed. São Paulo: Cortez, 1997. p. 69-90.

GARCIA, J. C. A Reforma da Educação Profissional: a dualidade assumida. 2012. 124 f. Dissertação (Mestrado em Educação - PUC Goiás). Goiânia, 2012.

ETG. Histórico da Escola Técnica Federal de Goiás. In. Livro do tombo. Goiânia: s.n., em 30 de junho de 1978, p. 198.

MARX, K.; ENGELS F. A ideologia alemã: teses sobre Feuerbach. São Paulo: Editora Centauro, 2005.

MLLER, M. T. A lousa e o torno: a Escola SENAI Roberto Mange de Campinas. 2009. 334f. Tese (Doutorado em Educação) - Universidade Estadual de Campinas), Campinas, 2009.

O ETG. Goiânia, setembro de 1945, p.1, Ano I, No 1. . Goiânia, maio de 1946, p.1, Ano II, Nº 5.

OLIVEIRA, D. E. M. B.; LESZCZYNSK, S. A. C. O papel da Comissão BrasileiroAmericana de Educação Industrial na configuração do ensino profissionalizante das escolas técnicas federais. In VIII Seminário Nacional de Estudos e Pesquisas: HISTEDBR Anais... Campinas, 2009. 


\section{SÁ, H. G. M. de. A transferência da escola de aprendizes artífices da Cidade}

de Goiás para a nova capital: contribuições para a construção da memória do IFG. 2014, 246 f. Dissertação (Mestrado em Educação) - Pontifícia Universidade Católica de Goiás). Goiânia, 2014.

SILVA, J.J. de A. e. Hélio Naves: um homem, uma história, uma missão. Goiânia: Kéops, 2006.

DENISE SILVA ARAÚJO é Mestre e Doutora em Educação (UFG). Graduada em Pedagogia - Orientação Educacional (PUC Goás). Professora Adjunta da Faculdade de Educação da UFG e professora aposentada do PPGE da PUC Goiás. Pesquisadora nas áreas de políticas e gestão educacional, formação e trabalho docente, educação profissional, educação infantil e infância. E-mail: denisearaujo17@gmail.com

HELVÉCIO GOULART MALTA DE SÁ é Mestre em Educação (PUC Goiás). Licenciado em História (PUC Goiás). Arquiteto e urbanista (PUC Goiás). Especialista em Engenharia de Segurança (UFG). Pesquisador nas áreas de políticas e gestão educacional, formação e trabalho docente, educação profissional. E-mail: helveciogms@gmail.com

IRIA BRZEZINSKI é Pós-doutora, Doutora em Administração da Educação (USP). Mestre em Planejamento Educacional (UnB). Graduada em Ciências Sociais e em Pedagogia - Orientação Educacional (UFPR). Professora titular da Pontifícia Universidade Católica de Goiás. Professora da Universidade de Brasília (aposentada). Desenvolve pesquisa em Políticas Educacionais, Planejamento e Gestão Educacional, Formação de Profissionais da Educação e Avaliação Institucional. Coordena o Grupo de Pesquisa: Políticas Educacionais e Gestão Escolar. Pesquisadora Bolsista Produtividade CNPq Nível 1. E-mail: iriaucg@ yahoo.com.br 